\title{
APONTAMENTOS PARA A ANÁLISE DO PAPEL DE UM SUBCENTRO EM UMA CIDADE MÉDIA: DOURADOS - MS ${ }^{1}$
}

\author{
Renato Massao Shiwa ${ }^{2}$ \\ Maria José Martinelli Silva Calixto ${ }^{3}$
}

Resumo: Este texto tem como objetivo analisar o processo de formação de novas centralidades intraurbanas em uma cidade média, a partir da análise do subcentro das ruas Fernando Ferrari e Filomeno João Pires, em Dourados-MS. Com base em um aporte teórico sobre o tema, consideramos sete critérios, na tentativa de comprovar a hipótese da pesquisa de que há nas referidas ruas a formação de um subcentro. Para a realização deste estudo, além de pesquisas bibliográficas, realizamos trabalho de campo, com a aplicação de questionários e/ou entrevistas junto aos moradores, comerciantes e prestadores de serviço da área estudada. Realizamos registros fotográficos, coleta de dados junto a Prefeitura Municipal e levantamento do uso do solo com base na tabela CNAE - Classificação Nacional de Atividades Econômicas. Destacamos que ainda há poucos estudos referentes às novas centralidades nas cidades médias. Neste sentido, acreditamos que esta pesquisa possa contribuir com as discussões acerca da temática.

Palavras-chave: Cidades Médias; Novas Centralidades; Subcentros; Dourados MS.

\section{APPOINTMENTS FOR THE ANALYSIS OF THE ROLE OF A SUBCENTER IN AN AVERAGE CITY: DOURADOS - MS}

Abstract: This text aims to analyze the process of formation of new intraurban centralities in a middle sized city, based on the analysis of the suburban streets of Fernando Ferrari and Filomeno João Pires, in Dourados-MS. Based on a theoretical contribution on the theme, we consider seven criteria, in an attempt to prove the hypothesis of the research that there is in the mentioned streets the formation of a subcenter. For the accomplishment of this study, in addition to bibliographical researches, we carried out field work, with the application of questionnaires and / or interviews with the residents, merchants and service providers of the studied area. We carry out photographic records, data collection with the City Hall and survey of land use based on the CNAE - National Classification of Economic Activities table. We emphasize that there are still few studies concerning the new centralities in the

\footnotetext{
${ }^{1}$ Este artigo é produto, parcialmente alterado e revisto do trabalho final de dissertação de mestrado desenvolvido na Faculdade de Ciências Humanas no Programa de Pós-Graduação em Geografia da Universidade Federal da Grande Dourados, UFGD, Dourados-MS.pgg@ufgd.edu.br

${ }^{2}$ Universidade Federal da Grande Dourados (UFGD). renatoshiwa@ hotmail.com

${ }^{3}$ Universidade Federal da Grande Dourados (UFGD). mjmartinelli@ yahoo.com.br

Estudos Geográficos, Rio Claro, 17(1): 115-140, jan./jun. 2019 (ISSN 1678-698X) http://www.periodicos.rc.biblioteca.unesp.br/index.php/estgeo
} 
medium cities. In this sense, we believe that this research can contribute to the discussions about the theme.

Keywords: Medium Cities; New Centralities; Subcenters; Dourados - MS.

\section{INTRODUÇÃO}

No que diz respeito à centralidade, podemos abordá-la sobre duas escalas que se diferenciam e se articulam - a interurbana e a intraurbana. Em linhas gerais, a primeira diz respeito a condição e expressão de central que uma cidade pode exercer em relação ao conjunto de cidades de sua rede urbana. Já a segunda, respeita as diferentes expressões de centralidade tomando como referência o território da cidade a partir de seu centro ou "centros" (SPOSITO, 1998, p. 27).

A expressão "centros" utilizada no plural pela autora refere-se às diferentes concentrações de atividades de comércio e serviços que se fazem presentes e que exercem papel de centralidade intraurbana - o centro principal e os demais centros que se formaram.

Em relação ao centro principal, Villaça (2001, p. 244) expõe que "caracteriza-se pela maior aglomeração de comércio e de serviços e menor concentração residencial, quando comparado com as demais partes centrais da cidade". E destaca "O centro principal exerce uma maior atração, ou polarização, mais constante sobre um número maior de pessoas".

Ainda, segundo o autor, mesmo que algumas áreas centrais que se constituíram fora do centro principal tenham atingido alto grau de diversidade em relação aos bens e serviços que ofertam, é no centro principal que ainda concentram-se a maior parte da infraestrutura urbana e os estabelecimentos comerciais e de serviços, tanto em quantidade quanto em diversidade (VILLAÇA, 2001, p. 244).

Tanto o centro principal quanto os demais centros que se consolidam em algumas cidades tornaram-se objeto de análise de vários estudiosos que defendem a importância de se considerar a articulação entre as escalas interurbana e intraurbana para uma real compreensão da estrutura interna da cidade. Entre eles destacamos Sposito (2001, p. 235) que defende:

Temos então, que considerar a necessidade crescente de articular duas escalas diferentes para uma análise mais consequente das mudanças por que passam as cidades, através da verificação dos fluxos intraurbanos e interurbanos.

Sendo assim, buscaremos tecer algumas considerações referentes ao papel de centralidade interurbana desempenhado por Dourados-MS e às transformações decorrentes deste processo que altera o espaço urbano e constitui novas expressões de centralidade intraurbana, considerando que este é um processo em constante transformação.

Dourados (Figura 01) localiza-se no centro-sul do estado de Mato Grosso do Sul. Sua área territorial é de $4.086,387 \mathrm{~km}^{2}$ e a área urbana $84,125 \mathrm{~km}^{2}$. Segundo dados do IBGE 2010 (Instituto Brasileiro de Geografia e Estatística) possui 196.035 habitantes.

Estudos Geográficos, Rio Claro, 17(1): 115-140, jan./jun. 2019 (ISSN 1678-698X) http://www.periodicos.rc.biblioteca.unesp.br/index.php/estgeo 


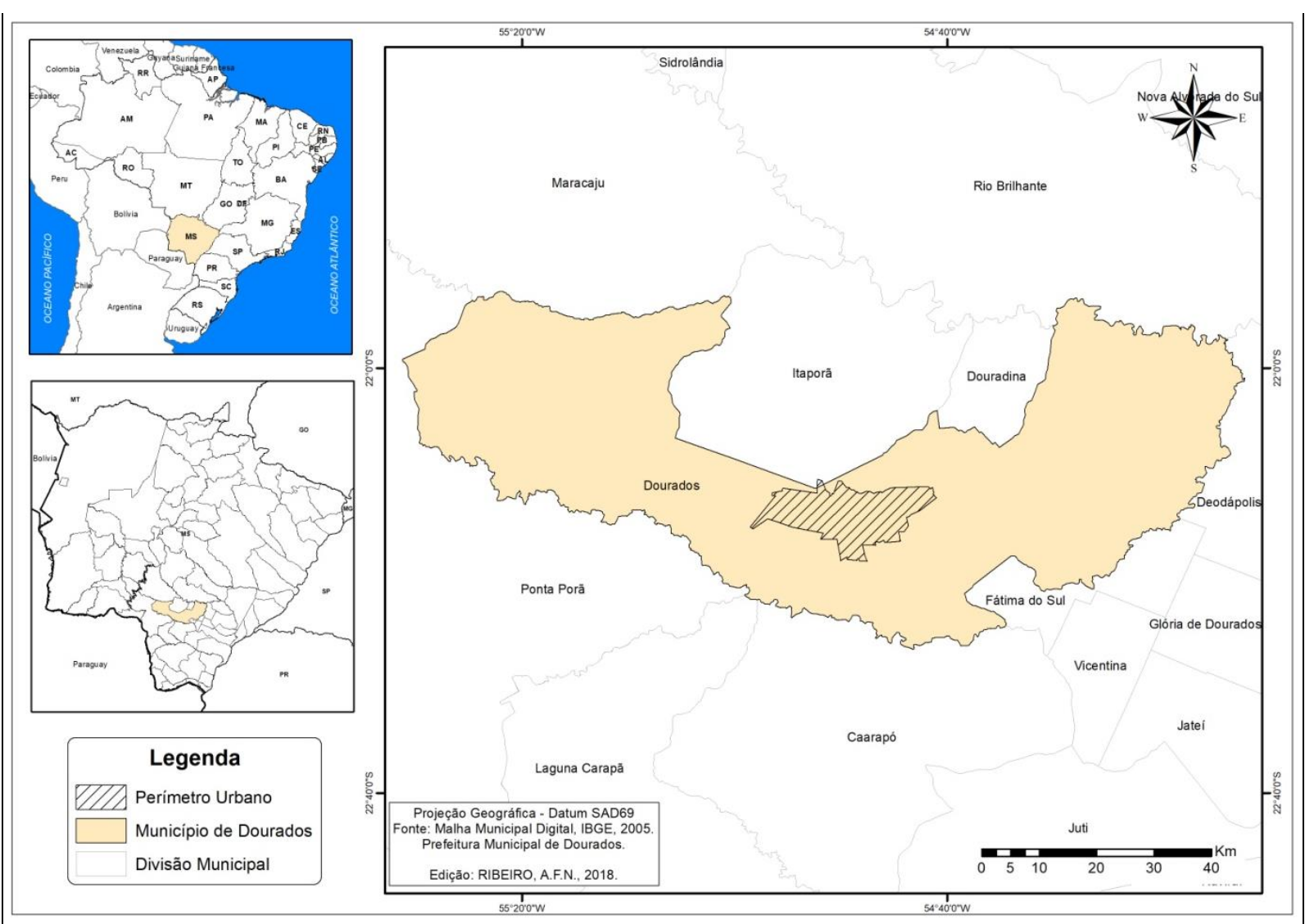

Figura 01 - Dourados - MS (2018): Localização do município.

Fonte: Malha Municipal Digital, IBGE, 2005.

Org.: Renato Massao Shiwa.

Tratando-se da centralidade interurbana e do papel das cidades médias na rede urbana, Castelo Branco (2007, p. 90) argumenta que:

As cidades médias constituem nós da rede urbana e servem a sua área de influência como pontos de prestação de serviços em escala regional. Seu tamanho populacional e área de atuação variam segundo características geográficas das regiões onde estão inseridas.

Neste sentido, as relações regionais variam conforme os níveis de interação entre as cidades médias e os outros centros de sua rede urbana.

Portanto, as cidades médias atraem investimentos na medida em que estas possuem um mercado consumidor que envolve não só os habitantes que residem na cidade, mas também a população de centros urbanos menores localizados em sua rede urbana.

Pautando-se nas ideias de Corrêa (2005), Calixto (2011, p. 2) defende que:

Cada centro urbano pode inserir-se, ao mesmo tempo, em diferentes redes urbanas, exercendo também papéis diferenciados em cada uma delas. Isso revela que a rede urbana configura-se e reconfigurase socioespacialmente de acordo com o contexto histórico.

Relacionando esta discussão apresentada com a realidade de Dourados, Calixto (2011, p. 2) completa:

Estudos Geográficos, Rio Claro, 17(1): 115-140, jan./jun. 2019 (ISSN 1678-698X) http://www.periodicos.rc.biblioteca.unesp.br/index.php/estgeo 
Embora Dourados (cuja condição pode variar espaço-temporalmente, de acordo com a sua especialização funcional) esteja ligada à rede urbana de Campo Grande e, por intermédio dela, à grande metrópole nacional - São Paulo - Também desempenha simultaneamente um papel singular e complementar a outros centros urbanos do seu entorno. Ou seja, há uma divisão/diferenciação que, no seu movimento, promove a integração/articulação. Assim, Dourados apresenta-se como um capital regional $B$ que se subordina a uma capital regional A (Campo Grande - MS) e, por meio desta, à rede urbana de São Paulo (grande metrópole nacional) e, ao mesmo tempo, com uma capital regional na sua área de influência imediata à qual assegura e é por ela assegurada, haja vista que as demandas regionais garantem, por exemplo, a condição de centralidade de Dourados.

A figura 02 apresenta a posição de Dourados com relação aos 34 centros urbanos que constituem sua rede urbana. Observamos que mesmo que um centro urbano esteja ligado a uma determinada rede não significa necessariamente que este centro não possa estar ligado a outras redes urbanas. No entanto, desempenhará papéis diferentes em cada uma delas. Assim, ao mesmo tempo em que Dourados possui papel "subordinado" na rede urbana da capital regional Campo Grande e da grande metrópole São Paulo, também é caracterizada por sua centralidade interurbana em sua área de influência, uma vez que desempenha papéis que atendem à demanda local e regional, garantindo assim sua posição de centralidade.

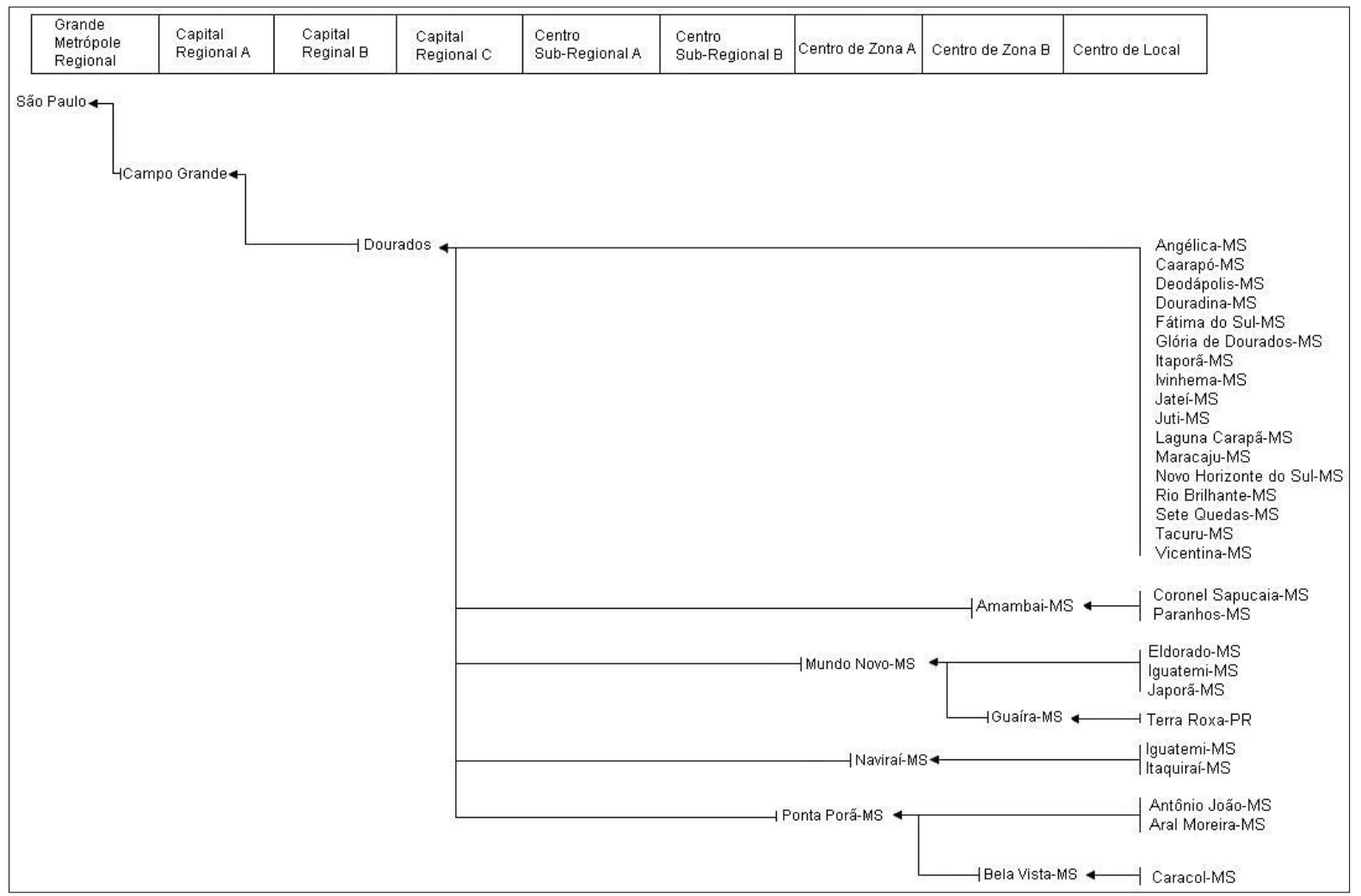

Figura 02 - Dourados-MS (2008): Posição na rede urbana.

Fonte: Regiões de Influência das Cidades, 2008.

Org.: SILVA, Valéria Ferreira.

Estudos Geográficos, Rio Claro, 17(1): 115-140, jan./jun. $2019 \quad$ (ISSN 1678-698X) http://www.periodicos.rc.biblioteca.unesp.br/index.php/estgeo 
A cidade de Dourados conta com uma variedade de comércio e serviços que além de atender, conforme já mencionamos, a população local, também atende consumidores de outros centros urbanos da região, tais como: Fátima do Sul, Laguna Carapã, Deodápoles, Douradina, Itaporã, Rio Brilhante, Ponta Porã, Amambai, Mundo Novo, Caarapó, Glória de Dourados, Vicentina, Maracaju, entre outras. Em Dourados, destacam-se: hipermercados e supermercados como Extra, Assaí, Atacadão e ABEVÊ (rede regional); Universidades públicas e privadas (UFGD, UEMS, UNIGRAN, Anhanguera e Seminário Teológico Batista); hospitais especializados; trabalho nos setores da indústria, agronegócio, comércio e construção civil; lazer (shopping e cinema); entre outros.

Sobre este viés, a cidade de Dourados desempenha papel de centralidade interurbana, decorrente da oferta de comércio e serviços que atendem à demanda local e regional. Nesse sentido, são as relações/articulações entre Dourados e os demais centros urbanos de sua área de influência que asseguram sua condição de centralidade. (CALIXTO, 2011, p. 4).

Destacarmos três pontos centrais em relação à condição de centralidade interurbana de Dourados na rede urbana em que se encontra inserida, sendo que estes pontos estão articulados entre si:

1) Seu caráter de cidade média e sua localização geográfica próxima a outras cidades;

2) Os grupos econômicos voltados à gestão territorial tendem a adotar estratégias que resultam na escolha de cidades que possam atrair mercado consumidor de várias cidades;

3) Consumidores de outros centros urbanos buscam em Dourados os bens e serviços que não encontram em sua cidade de origem. Essa relação não deve ser entendida como de mão única, uma vez que, Dourados também depende destas cidades como mercado consumidor para garantir sua condição de centralidade.

Desta forma, a centralidade interurbana esta articulada com a centralidade intraurbana, pois, a condição de central que uma cidade média exerce, em decorrência dos papéis que passaram a desempenhar em sua rede urbana, influencia na estrutura interna da cidade, pois, a aplicação de investimentos que visam atrair o mercado consumidor regional, influem na redefinição da estrutura intraurbana. Este processo, ao mesmo tempo em que constitui áreas centrais, onde se concentram maior parte do comércio e serviços, como por exemplo, o centro principal, também, condiciona o afastamento da população de menor poder aquisitivo, que não possui condições de morar e/ou de ter acesso à cidade em seu conjunto.

De acordo com Calixto (2000, p. 162) "Nessa perspectiva, a configuração urbana revela tanto riqueza como pobreza, tanto a concentração como 0 distanciamento, como base e expressão de novas lógicas de localização".

Neste sentido, o centro principal, constitui-se como local de concentração de comércio e serviços, onde também se fazem mais presente maiores investimentos em infraestrutura urbana. $O$ preço mais elevado dos seus terrenos faz com que aqueles que não possuem poder aquisitivo para comprar ou alugar imóveis nessa área da cidade, tenham que morar em locais distantes dos que ofertam bens e serviços. Este fator foi evidenciado durante a pesquisa de campo nos loteamentos

Estudos Geográficos, Rio Claro, 17(1): 115-140, jan./jun. 2019 (ISSN 1678-698X) http://www.periodicos.rc.biblioteca.unesp.br/index.php/estgeo 
Vila Industrial, Jardim São Cristóvão, Jardim João Paulo II e Parque das Nações I, localizados na zona periférica de Dourados.

Esses loteamentos consolidaram o surgimento da periferia em Dourados. Segundo Calixto (2000, p. 162) "os loteamentos marcaram a ocupação dos segmentos sociais de menor poder aquisitivo a partir da década de 1970".

Os levantamentos demonstraram que estes loteamentos destinaram-se, sobretudo, a moradores de menor poder aquisitivo vindos da área rural de Dourados e pessoas de outros centros urbanos que buscavam na cidade melhores oportunidades de vida.

O distanciamento desses loteamentos da em relação ao centro principal (local de maior concentração das atividades terciárias) estimulou o surgimento de comércio e serviços que ao logo dos anos foram se instalando, sobretudo nas ruas Fernando Ferrari e Filomeno João Pires, como forma de atender às necessidades da população local.

A consolidação destas atividades conferiu ao local característica de subcentro que passou a atender, também, bairros adjacentes cuja população viu a possibilidade de atender suas demandas, haja vista que o subcentro oferece bens e serviços que antes eram encontrados apenas no centro principal. Por esta razão, destaca-se como alternativa para os consumidores locais e próximos a ele, que não querem ou não possuem condições de se deslocar em busca de serviços em áreas mais distantes.

Atualmente, o local dispõe de comércio e serviços diversificados, entre eles: farmácias, pizzarias, lojas de roupas, restaurantes, supermercados, gráficas de artes de comunicação visual, loja de móveis, estúdio fotográfico, clínica de estética, escritórios de contabilidade, clínica veterinária, consultório odontológico, lojas de conveniências, lojas de assistência técnica, oficinas de motos, distribuidoras de gás e água mineral, lojas de utilidades domésticas, lojas de tintas e materiais para construção, distribuidora de embalagens, salões de beleza, estúdio de piercing e tatuagens. Conta também com oficina para veículos, distribuidora de sementes, bicicletarias, metalúrgica, borracharias, casa agropecuária, tapeçaria, lava jatos, loja de sistemas de segurança, tornearia, lojas de som automotivo, loja de alinhamento e balanceamento de veículos, loja de materiais elétricos, loja de refrigeração, loja de brinquedos, distribuidora de catálogos e agência de turismo.

Neste sentido, conforme aponta Villaça (2001, p. 293):

Alguns pontos da cidade - nos bairros - que se caracterizavam, de modo predominantemente, pela função residencial, desenvolveramse também, com intensidade e complexidade, muitos daqueles serviços até então só encontrados na área central. Assim, atualmente, em outros bairros, proliferam, lojas comerciais, consultórios, bancos, cinemas, escolas, restaurantes, bares, para atender a população residente no local, ou nas suas proximidades.

Ainda segundo Villaça (2001, p. 293) "esses bairros, dispondo dos serviços assinalados, representam um papel complementar, de centro de atividades, sendo, portanto, denominados subcentros". E, nesse sentido, podemos dizer que nas ruas Fernando Ferrari e Filomeno João Pires (Figura 03), há a formação de área com característica de um subcentro.

Sendo assim, tomamos como recorte espacial de análise as atividades de comércio e serviços existentes nas referidas ruas, localizadas nos loteamentos, Vila

Estudos Geográficos, Rio Claro, 17(1): 115-140, jan./jun. 2019 (ISSN 1678-698X) http://www.periodicos.rc.biblioteca.unesp.br/index.php/estgeo 
Industrial, Jardim São Cristóvão, Jardim João Paulo II e Parque das Nações I, sendo esses, quando consideramos a realidade de uma cidade média, caracterizados pelo seu distanciamento em relação ao centro principal.

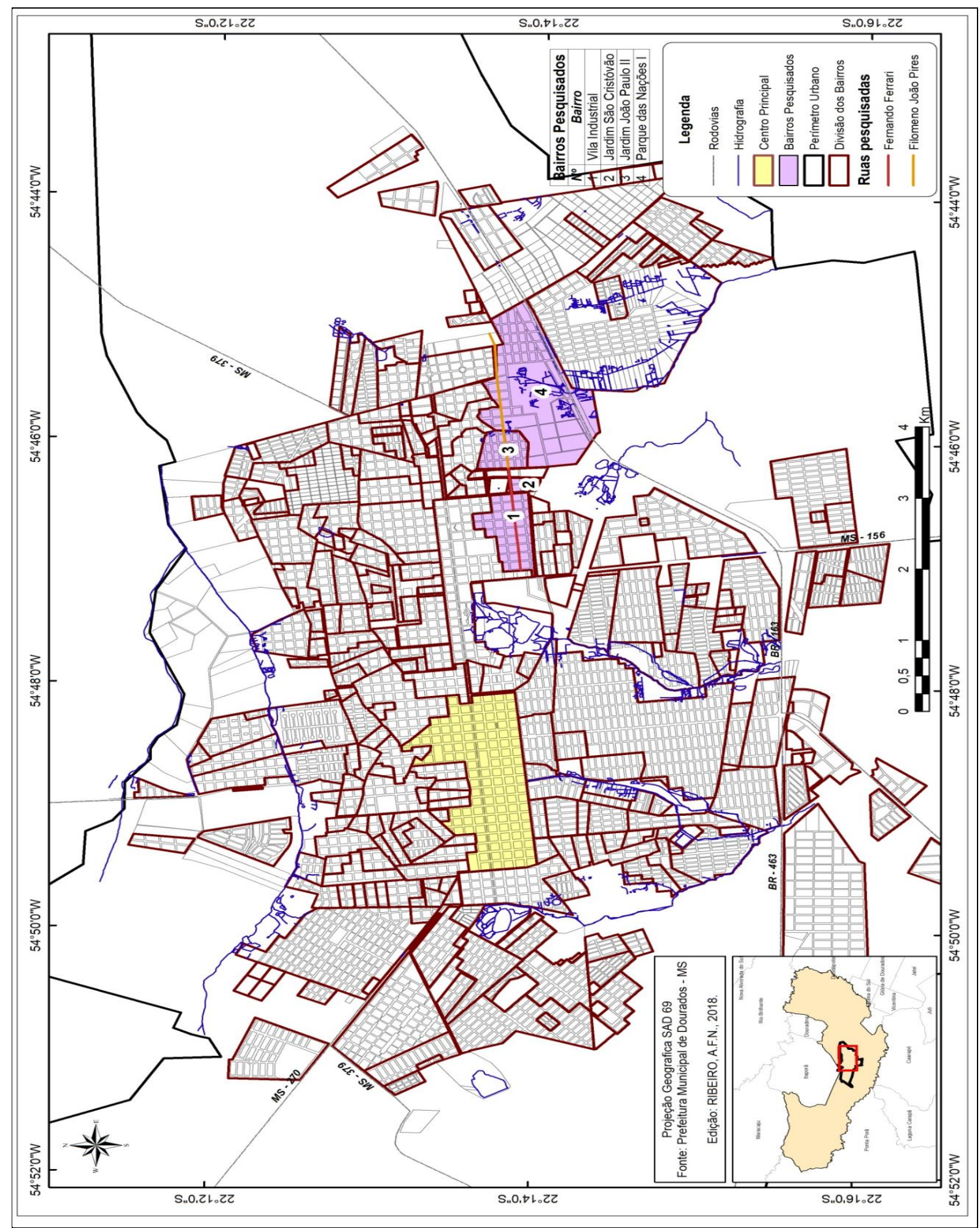

Figura 03 - Dourados - MS (2018): Localização das ruas Fernando Ferrari e Filomeno João Pires nos loteamentos Vila Industrial, Jardim São Cristóvão, Jardim João Paulo II e Parque das Nações I.

Fonte: Prefeitura Municipal de Dourados - MS, 2018.

Org.: SHIWA, Renato Massao.

Estudos Geográficos, Rio Claro, 17(1): 115-140, jan./jun. $2019 \quad$ (ISSN 1678-698X) http://www.periodicos.rc.biblioteca.unesp.br/index.php/estgeo 
A escolha dessas ruas como objeto de estudo deu-se em razão da expressiva presença de comércio e serviços observados durante a pesquisa de campo, os quais se encontram distribuídos por quase toda a sua extensão e atraem consumidores locais e de outras áreas da cidade. Na Tabela 01 podemos observar a distância dos loteamentos em relação ao centro principal.

Tabela 01 - Dourados - MS (2018): Distância entre os loteamentos e o centro

\begin{tabular}{c|c|c|c}
\hline \multicolumn{1}{c|}{ LOTEAMENTO } & TRAJETO & $\begin{array}{c}\text { DISTÂNCIA } \\
\text { (KM) }\end{array}$ & $\begin{array}{c}\text { TEMPO DE } \\
\text { LOCOMOÇÃO }\end{array}$ \\
\hline Vila Industrial & $\begin{array}{c}\text { Via Av. Marcelino } \\
\text { Pires e Rua } \\
\text { Fernando Ferrari }\end{array}$ & 3,5 & 11 min (carro) \\
Jardim São Cristóvão min (a pé)
\end{tabular}

Fonte: Google Maps, 2018.

Org.: SHIWA, Renato Massao.

Nota-se que a distância entre os loteamentos e o centro principal é relativamente pequena quando comparado com a realidade metropolitana. Isto mostra a especificidade das cidades médias que, geralmente, possuem menor extensão territorial. No entanto, reforçamos que este distanciamento vai além do fator físico, pois, deve ser considerado, principalmente, o fator socioeconômico dos moradores. Durante a pesquisa de campo observou-se que boa parte dos moradores apresenta dificuldades de mobilidade para outras áreas mais distantes da cidade. Como principais motivos, alegam não possuir transporte privado e a deficiência do transporte público coletivo - o alto preço da passagem e a má qualidade do serviço.

\section{DELIMITAÇÃO E CARACTERIZAÇÃO DO SUBCENTRO DAS RUAS FERNANDO FERRARI E FILOMENO JOÃO PIRES}

Visando a delimitação e caracterização do subcentro das ruas Fernando Ferrari e Filomeno João Pires, foram utilizados critérios embasados em três categorias de comércio e serviços denominadas: Atividades Centrais, Atividades Não Centrais e Atividades Típicas da Zona Periférica Central (ZPC). Tais categorias foram desenvolvidas a partir de autores, tais como: Burgess (1925), Murphy e Vance Junior (1954), Colby (1958), Horwood e Boyce (1959), Hoyt (1959), Aloísio Duarte (1967), Haidine Duarte (1974) e Strohaecker (1988).

Estudos Geográficos, Rio Claro, 17(1): 115-140, jan./jun. 2019 (ISSN 1678-698X) http://www.periodicos.rc.biblioteca.unesp.br/index.php/estgeo 
Essas análises se embasaram em estudos da Escola de Chicago, tendo como principal modelo - as zonas ou anéis concêntricos - proposto por Burgess em 1925. Este modelo baseia-se na expansão da cidade de Chicago a partir do Central Business District - CDB $^{4}$ (STROHAECKER, 1988, p. 172).

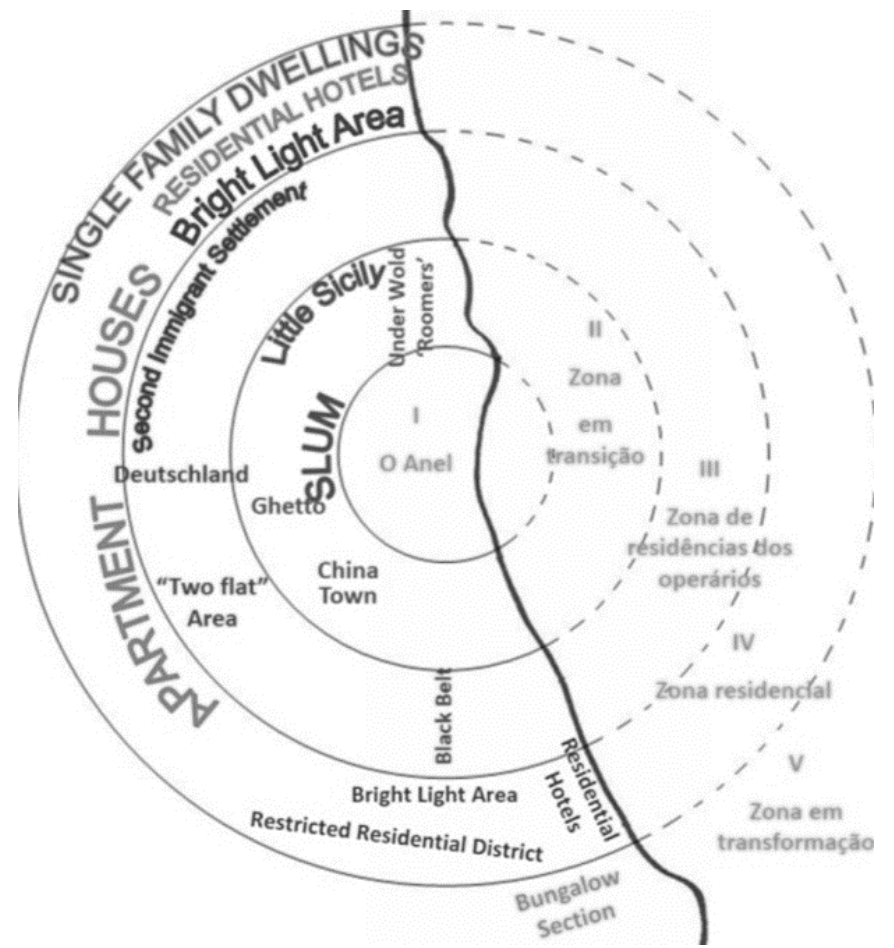

Figura 04 - Modelo de zonas ou anéis concêntricos de Burgess - 1925.

Fonte: BURGESS, E. W. 1925.

O primeiro anel caracteriza-se pelo uso intensivo do solo para fins comerciais e de prestação de serviços (Núcleo Central), onde estão inseridos três grupos de estabelecimentos que se caracterizam na categoria de Atividades Centrais de consumo frequente e pouco frequente: 1) lojas de departamento que oferecem em seus locais uma vasta variedade de produtos, tais como alimentos, roupas, calçados, acessórios, mobiliários, decoração, cosméticos, drogarias, eletrônicos, brinquedos, etc.; 2) escritórios e consultórios de profissionais liberais e as instituições de serviços financeiros; 3) estabelecimentos associados e dependentes dos citados anteriormente no grupo 1 e 2, como, por exemplo, restaurantes, gráficas e papelarias (STROHAECKER, 1988, p. 173).

O segundo anel é denominado por Burgess (1925) de "zona de transição". Com base no modelo proposto por esse autor, Strohaecker (1988, p. 173) expõe:

A zona de transição descrita por Burgess tem sua origem na transformação que ocorreu nas cidades com o advento da fase industrial do capitalismo. A cidade passou então a desempenhar diferentes funções que resultaram, por sua vez, em novas formas espaciais distintas e segregadas [...] a zona de transição pode ser conceituada como uma área mista com indústrias, oficinas, depósitos e residências superlotadas, subdivididas e degradadas.

\footnotetext{
${ }^{4}$ Em português - Distrito Central de Negócios - refere-se ao Núcleo Central da cidade cujo conceito foi desenvolvido por Burgess em 1925 (STROHAECKER, 1988, p. 172).

Estudos Geográficos, Rio Claro, 17(1): 115-140, jan./jun. $2019 \quad$ (ISSN 1678-698X) http://www.periodicos.rc.biblioteca.unesp.br/index.php/estgeo
} 
No entanto, o conteúdo físico e social da zona de transição mudou desde a formulação do modelo de Burgess. Esta transformação se deu em razão da zona de transição localizar-se mais próxima do Núcleo Central do que as demais áreas propostas pelo modelo de zonas ou anéis concêntricos, tornando-a atrativa para a entrada de comércios advindos do Núcleo Central, que passava por um processo de descentralização de suas atividades em decorrência do alto custo imobiliário de seus imóveis e da falta de área física para expansão. Nesse sentido, Burgess propõe, que a tendência é cada zona estender sua área até a zona posterior imediata (STROHAECKER, 1988, p. 173).

A descentralização de comércio e serviços por meio da saída de alguns estabelecimentos do Núcleo Central em direção à zona de transição reestruturou o espaço urbano nessa zona da cidade. Segundo Strohaecker (1988, p. 173), "a partir de então vários estudiosos procuraram conceituar esta zona a partir de uma visão mais atual". Assim, ainda segundo a mesma autora, "Em 1959, Horwood e Boyce introduzem o conceito de Zona Periférica Central (ZPC) descrevendo minuciosamente suas características, diferenças e relações espaciais".

Conforme o conceito de Horwood e Boyce (1959), a ZPC caracteriza-se pelo uso semi-intensivo e diversificado de atividades comerciais de consumo frequente e pouco frequente e pela diminuição gradual de uso do solo para fins residenciais. Quanto às Atividades Típicas da Zona Periférica Central (ZPC), além das indústrias, oficinas, depósitos e comércio atacadista (primeiras atividades que se deslocarem do Núcleo Central para a ZPC), foram se deslocando, também, comércios varejistas, sobretudo, aquelas que apresentavam dificuldades em se desenvolver no Núcleo Central em razão dos altos custos imobiliários e/ou por necessitarem de maior área para se desenvolver. Entre essas atividades citamos conveniências, materiais para construção, assistência técnica, distribuidoras, entre outras (STROHAECKER, 1988, p. 173).

O terceiro e quarto anel, caracterizam-se pelo uso predominantemente residencial de segmentos de médio e baixo poder aquisitivo. Nestas zonas residem operários, pequenos comerciantes, vendedores, profissionais liberais e trabalhadores em geral que necessitam morar próximos ao seu local de trabalho. 0 quinto anel corresponde aos subúrbios e núcleos satélites, onde se encontram as melhores residências. (STROHAECKER, 1988, p. 174).

A categoria de Atividades Não Centrais, sendo os comércios de consumo cotidiano da população, isto é, as atividades que estão distribuídas por todos as áreas da cidade, e, por esta razão, atendem apenas consumidores do local onde encontram-se inseridas, uma vez que não apresentam poder de atração de consumidores de outras localidades, tais como, padarias, sorveterias, lanchonetes, açougues, bares, pequenos mercados, salões de cabeleireiros, entre outros (DUARTE, 1974, p. 87).

Desta forma, embasada nas três categorias mencionadas, a delimitação e caracterização do subcentro das ruas Fernando Ferrari e Filomeno João Pires será proposta levando-se em conta os seguintes critérios:

1) Predominância de comércio e serviços no uso do solo da área delimitada;

2) Maior concentração de Atividades Centrais e Típicas da Zona Periférica Central (ZPC) em relação as Atividades Não Centrais;

3) Presença de serviços de profissionais liberais;

4) Existência de serviços financeiros;

Estudos Geográficos, Rio Claro, 17(1): 115-140, jan./jun. 2019 (ISSN 1678-698X) http://www.periodicos.rc.biblioteca.unesp.br/index.php/estgeo 
5) Instalação de comércio pertencente à rede de filiais;

6) Serviço cultural e recreativo;

7) Serviços de meios de transporte coletivo.

\section{O SUBCENTRO DAS RUAS FERNANDO FERRARI E FILOMENO JOÃO PIRES}

Atualmente, encontram-se distribuídos na Vila Industrial, Jardim São Cristóvão, Jardim João Paulo II e Parque das Nações I, uma variedade de comércio e serviços que atendem não só a população dos quatro loteamentos, mas também, os consumidores de outras localidades, tanto próximas, quanto mais distantes. A maior parte do comércio e serviços, como já dito, concentram-se nas ruas Fernando Ferrari e Filomeno João Pires.

Dessa forma, primeiramente, optou-se por realizar o mapeamento do uso do solo em toda a extensão das duas ruas citadas. Após análise do uso do solo, apresentaremos a delimitação e caracterização do objeto de pesquisa. Para isso, utilizaremos os sete critérios já mencionados, que foram embasados nas três categorias de atividades, sendo elas: Atividades Centrais, Atividades Típicas da Zona Periférica Central (ZPC) e Atividades não Centrais. Esta classificação foi necessária porque conforme a bibliografia é a partir da concentração de Atividades Centrais e Típicas da Zona Periférica Central (ZPC), referente ao comércio de consumo frequente e pouco frequente, que se pode caracterizar um subcentro, tendo em vista que as Atividades não Centrais de consumo cotidiano não são suficientes para caracterizá-lo.

Por meio do mapeamento do uso do solo no trajeto que percorre toda a extensão das ruas Fernando Ferrari e Filomeno João Pires $(3,5 \mathrm{Km})$ encontramos a presença de comércio e serviços, residências, instituições públicas e privadas, terrenos não edificados e salões desocupados, para alugar e/ou em construção.

Para fins de representação, devido à extensão das ruas em questão (Fernando Ferrari 1,5 km e Filomeno João Pires $2 \mathrm{~km}$, totalizando 3,5 km), optamos por subdividi-las em 06 zonas (Figura 05) que facilitarão a análise do objeto de estudo. Contudo, vale esclarecer que a referida subdivisão se dará apenas para fins de representação, haja vista que consideramos a área em sua totalidade.

Estudos Geográficos, Rio Claro, 17(1): 115-140, jan./jun. 2019 (ISSN 1678-698X) http://www.periodicos.rc.biblioteca.unesp.br/index.php/estgeo 
Apontamentos para a análise...

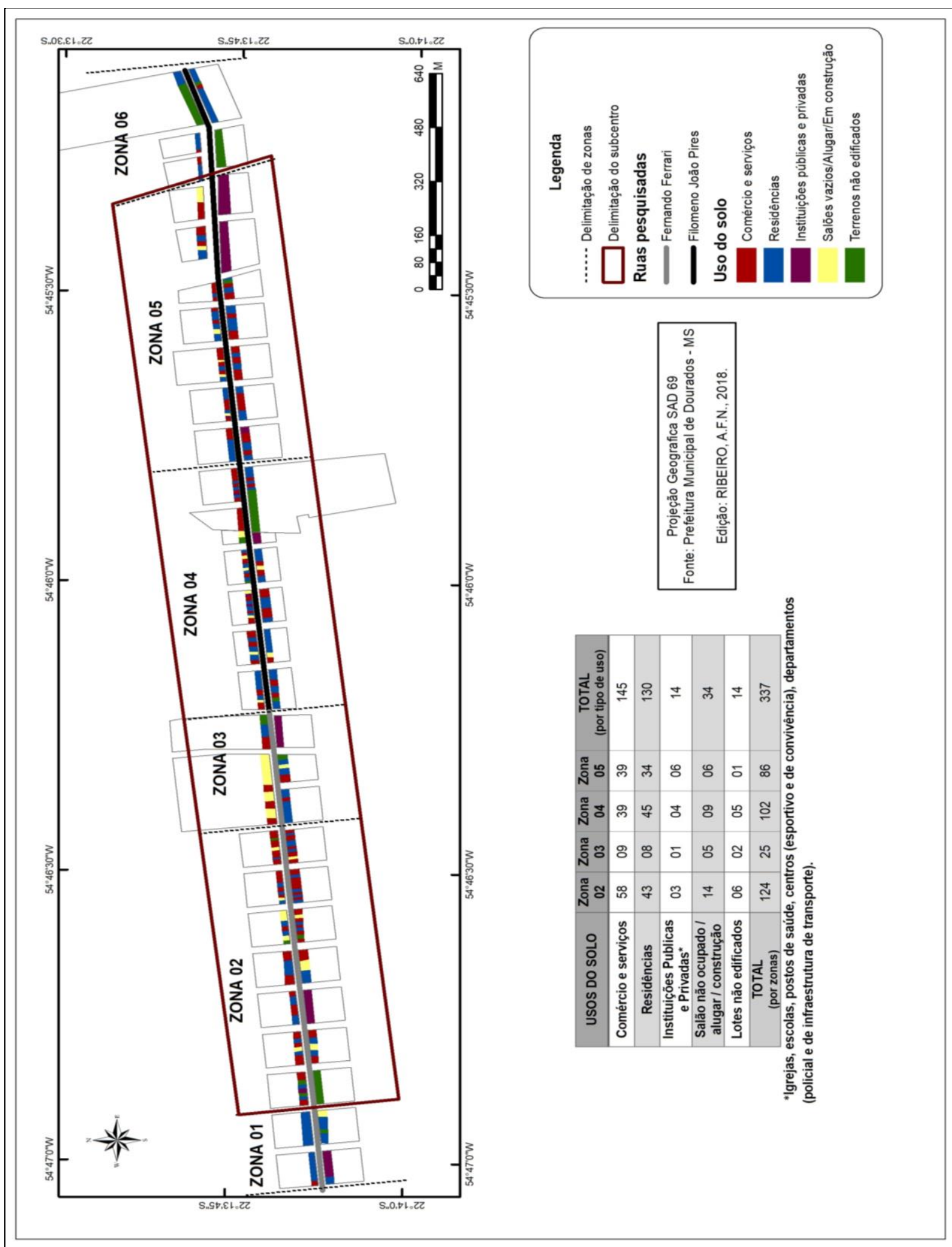

Figura 05 - Dourados - MS (2018): Delimitação da área de pesquisa nas ruas Fernando Ferrari e Filomeno João Pires.

Fonte: SHIWA, Renato Massao, 2018.

Estudos Geográficos, Rio Claro, 17(1): 115-140, jan./jun. 2019 (ISSN 1678-698X) http://www.periodicos.rc.biblioteca.unesp.br/index.php/estgeo 
Conforme pudemos observar na figura 05 , seguindo a direção oeste para leste, o primeiro setor, a zona 01, localizada na Vila Industrial, nas duas primeiras quadras da Rua Fernando Ferrari, o uso do solo destaca-se predominantemente para fins residenciais, havendo apenas um comércio, uma Instituição Pública, um terreno não edificado e um salão desocupado.

A partir da terceira quadra da Rua Fernando Ferrari, até o seu final, nos setores da zona 02, que fica na Vila Industrial, e zona 03, no Jardim São Cristóvão, concentra-se a ocorrência de comércio e serviços. A presença frequente de atividades comerciais se estende ao quarto e quinto setores, a zona 04, situada no Jardim João Paulo II, que corresponde ao início da Rua Filomeno João Pires, e a zona 05, localizada no Parque das Nações I, entre a $7^{\text {a }}$ e a $12^{\underline{a}}$ quadra da Rua Filomeno João Pires.

Após o setor da zona 05, nas cinco últimas quadras da Rua Filomeno João Pires, que corresponde à zona 06, situada no Parque das Nações I, as áreas residenciais voltam a predominar, havendo, também, a presença de terrenos não edificados. Nessa Zona, encontraram-se instalados apenas dois comércios, uma Instituição Pública e um salão não ocupado.

$\mathrm{Na}$ Tabela 02, podemos observar a distribuição de comércio e serviços em toda a extensão das ruas Fernando Ferrari e Filomeno João Pires. Nota-se que nas zonas 01 e 06 são as que apresentam menor número de estabelecimentos.

\section{Tabela 02 - Dourados - MS (2018): Distribuição do comércio e serviços - Divisão por zonas}

\begin{tabular}{c|c|c|c|c|c|c}
\hline \multicolumn{7}{c}{ Distribuição do comércio e serviços - Divisão por zonas } \\
\hline Zona & 01 & 02 & 03 & 04 & 05 & 06 \\
\hline$N^{\circ}$ de estabelecimentos & 01 & 58 & 09 & 69 & 39 & 02 \\
\hline
\end{tabular}

Fonte: SHIWA, Renato Massao, 2018.

Neste sentido, conforme demonstrado na figura 05, optou-se por delimitar a área de pesquisa nos setores correspondentes às zonas 02, 03, 04 e 05, destacados na figura com a cor laranja, haja vista, que as zonas 01 e 06 apresentam de forma mais recorrente uso residencial e a presença de terrenos não edificados, não havendo número significativo de comércio e serviços.

Sendo assim, a delimitação da área de pesquisa compreende aos setores compostos pelas zonas 02, 03, 04, 05, localizadas em trechos das ruas Fernando Ferrari e Filomeno João Pires, abrangendo uma extensão de 2,7 km. Destacamos que se comparado com as demais zonas da área delimitada, a zona 03 apresenta quantidade baixa de atividades terciárias (9 estabelecimentos). Isso ocorre em razão dessa zona possuir apenas 3 quadras, e, dessa maneira, uma dimensão territorial menor em relação às demais zonas. Além disso, os estabelecimentos distribuídos pela zona 03 ocupam áreas maiores, pois trata-se de: supermercados, lojas de móveis e pizzarias. Na Tabela 03, podemos verificar o uso do solo na área delimitada como subcentro.

Estudos Geográficos, Rio Claro, 17(1): 115-140, jan./jun. $2019 \quad$ (ISSN 1678-698X) http://www.periodicos.rc.biblioteca.unesp.br/index.php/estgeo 
Tabela 03 - Dourados - MS (2018): Uso do solo no subcentro das ruas Fernando Ferrari e Filomeno João Pires

\begin{tabular}{c|r|r}
\hline USOS DO SOLO & N.o TOTAL & \multicolumn{1}{c}{$\%$} \\
\hline Comércio e serviços & 145 & $44 \%$ \\
\hline Residências & 130 & $39 \%$ \\
\hline $\begin{array}{c}\text { Instituições (igreja, escola, posto de saúde, departamento } \\
\text { policial) }\end{array}$ & 13 & $4 \%$ \\
\hline Salão não ocupado/ em construção & 33 & $10 \%$ \\
\hline Lotes não edificados & 10 & $3 \%$ \\
\hline TOTAL & 331 & $100 \%$ \\
\hline
\end{tabular}

Fonte: SHIWA, Renato Massao, 2018.

Do total de 331 unidades de uso do solo, 145 (44\%) destina-se para fins de comércio e serviços. As residências correspondem a 130 unidades (39\%) e as instituições, 13 unidades (4\%). Enquanto que os salões não ocupados/ em construção, e os lotes não edificados, representam 33 unidades (10\%) e 10 unidades $(3 \%)$ respectivamente.

Uma vez delimitada a área do subcentro, faz-se necessário caracterizar o comércio e serviços presentes na área de pesquisa através dos critérios adotados como metodologia para se confirmar a hipótese de que se trata de um subcentro.

Dessa forma, ao analisarmos os dados de uso do solo na área delimitada nas ruas Fernando Ferrari e Filomeno João Pires, referentes apenas ao comércio e serviços, às residências e aos salões não ocupados ou em construção chegamos ao seguinte resultado:

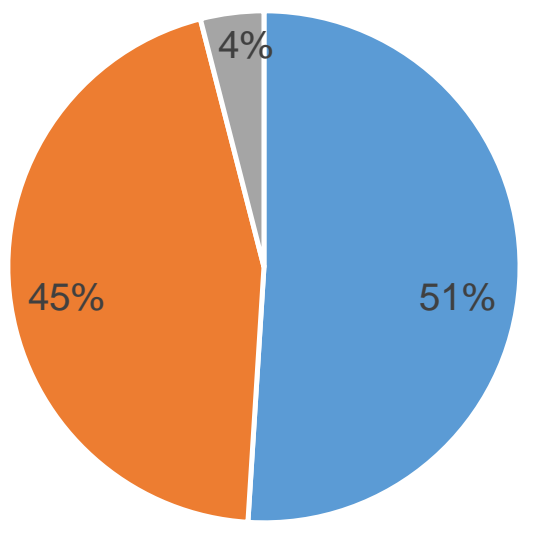

- Comércios e Serviços

- Redidências

- Instituições

Figura 06 - Dourados - MS (2018): Uso do solo nas ruas Fernando Ferrari e Filomeno João Pires (\%).

Fonte: SHIWA, Renato Massao, 2018.

O número total de comércio e serviços $(51 \%)$ é superior à soma do número de residências (45\%) e lotes não edificados (4\%). Isto é, se somarmos a quantidade dos dois segmentos chegamos a $49 \%$, valor inferior ao de comércio e serviços. Esses dados confirmam o primeiro critério referente à predominância de atividades terciárias em relação ao uso do solo na área delimitada, pois, mostram que a Estudos Geográficos, Rio Claro, 17(1): 115-140, jan./jun. 2019 (ISSN 1678-698X) http://www.periodicos.rc.biblioteca.unesp.br/index.php/estgeo 
quantidade de comércio e serviços é superior, e, mesmo que sejam construídas residências nos lotes ainda não edificados, não ultrapassará o número de tais atividades. Além disso, os salões não ocupados (que encontram-se para alugar e/ou em construção) somam 33 unidades ( $10 \%$ do total de uso no solo), demonstrando uma tendência de aumento no número de comércio e serviços, uma vez que observou-se durante a pesquisa de campo, a procura de imóveis comerciais por parte de futuros empreendedores.

Esse primeiro critério caracteriza o local como área de maior concentração do setor terciário, esse fator é importante para que se tenha um quantitativo do comércio e serviços existentes. Quanto mais servido destas atividades em quantidade e variedade, maior será o grau de atração que o subcentro exercerá. Levando-se em conta, também, o nível de consumo de seus frequentadores. No entanto, nem todos os estabelecimentos são característicos de subcentro, esse caracteriza-se pela predominância de comércio e serviços de consumo frequente e pouco frequente classificados como Atividades Centrais e Atividades Típicas da Zona Periférica Central (ZPC). Já o comércio de consumo cotidiano classificado como Atividades Não Centrais não caracterizam um subcentro (DUARTE, 1974, p. 87).

Sendo assim, caracterizamos os 145 estabelecimentos comerciais e de serviços delimitados na área, utilizando, conforme já dito, as três categorias: Atividades Centrais, Atividades Não Centrais e Atividades Típicas da Zona Periférica Central (ZPC). Conforme Figura 07.

Estudos Geográficos, Rio Claro, 17(1): 115-140, jan./jun. 2019 (ISSN 1678-698X) http://www.periodicos.rc.biblioteca.unesp.br/index.php/estgeo 
Apontamentos para a análise...

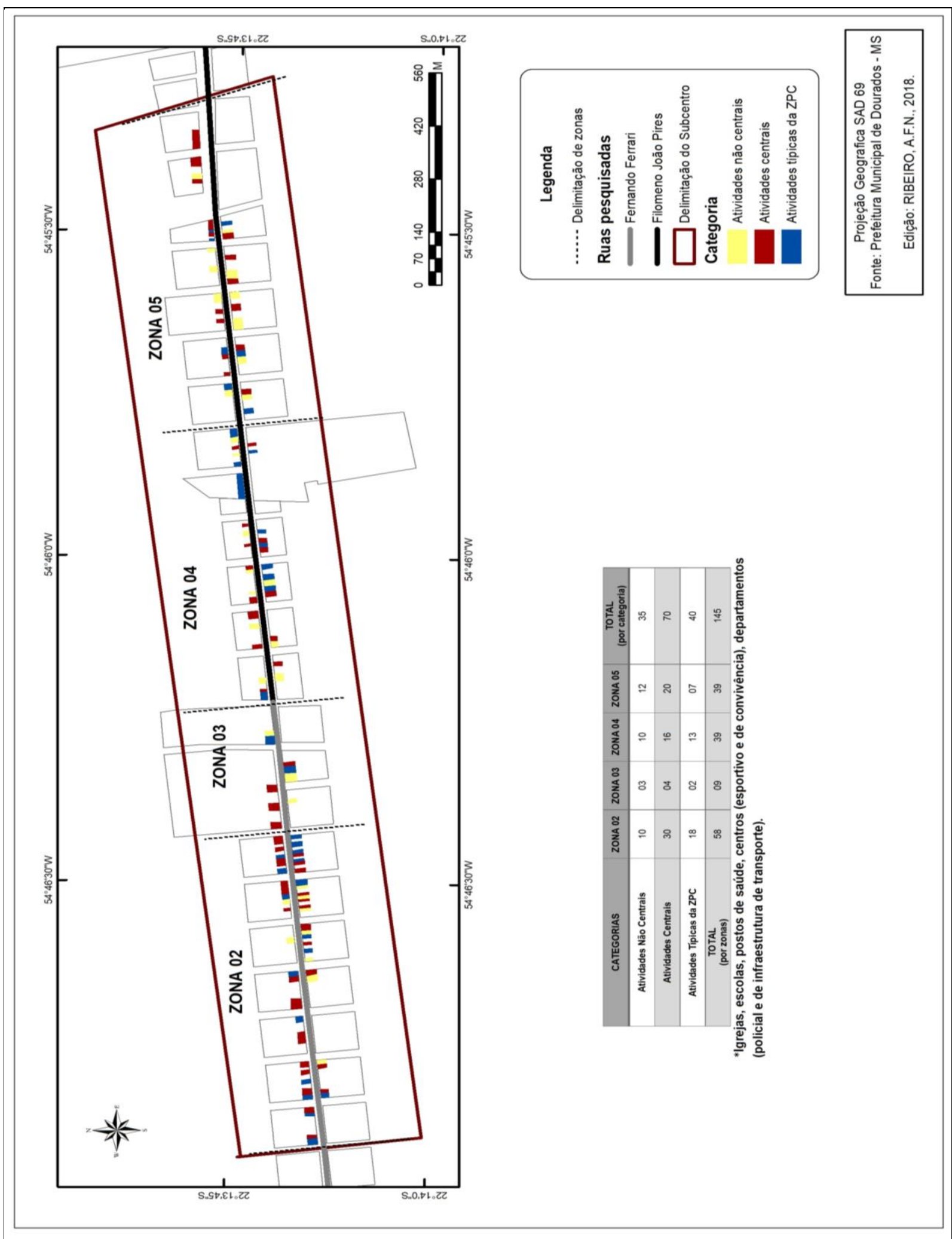

Figura 07 - Dourados - MS (2018): Categorias de Comércio e Serviços nas ruas Fernando Ferrari e Filomeno João pires

Fonte: SHIWA, Renato Massao, 2018.

Estudos Geográficos, Rio Claro, 17(1): 115-140, jan./jun. 2019 (ISSN 1678-698X) http://www.periodicos.rc.biblioteca.unesp.br/index.php/estgeo 
Ao classificar as atividades comerciais nas três categorias, encontramos: 70 unidades de Atividades Centrais (48,3\%), 40 unidades de Atividades Típicas da Zona Periférica Central (27,6\%), e 35 unidades de Atividades Não Centrais $(24,1 \%)$.

A categoria de Atividades Não Centrais representa $24,1 \%$, sendo assim, o comércio e serviços classificados nas categorias de Atividades Centrais e Atividades Típicas da Zona Periférica Central (ZPC), que caracterizam a formação de um subcentro, representam juntos $75,9 \%$ do total estabelecimentos encontrados. Assim, confirma-se o segundo critério relacionado ao maior número de comércio e serviços de consumo frequente e pouco frequente das Atividades Centrais e Típicas da Zona Periférica Central (ZPC) em relação ao comércio de consumo cotidiano das Atividades Não Centrais, reforçando assim, a existência de um subcentro.

$\mathrm{Na}$ categoria caracterizada como Atividades Não Centrais, está inserido o comércio de consumo cotidiano que atende basicamente os consumidores locais. Sendo assim, conforme apontou Duarte (1974), tais atividades definem o chamado comércio de bairro e não caracterizam a existência de um subcentro, pois não possuem forte poder de atração de consumidores de outros bairros da cidade. Entre os estabelecimentos dessa categoria encontramos: mercados, mercearias, açougues, bares, sorveterias, açaizeiros, salões de cabeleireiros, lojas de variedades, frutarias, barbearias, padarias, lanchonetes, academia de musculação e sacolão.

No entanto, importante destacar que alguns comerciantes que possuem comércio caracterizado como Atividades Não Centrais, alegaram atender consumidores de outros bairros da cidade. $O$ que ocorre é que tais consumidores que são atraídos pelos comércios das Atividades Centrais e Típicas da ZPC acabam utilizando, também, o comércio de Atividades Não Centrais. Desta forma, não negamos a sua importância no contexto geral de consumo no subcentro, uma vez que tais comércios também são utilizados pelos consumidores e contribuem para 0 fluxo de pessoas e mercadorias.

Esse fator nos mostra uma especificidade em Dourados, onde observamos que as Atividades Não Centrais formam um conjunto com as demais categorias de atividades. Nessa lógica, a centralidade exercida pelo subcentro Fernando Ferrari e Filomeno João Pires se constitui pelo conjunto de todas as atividades nele presente. Porém, cabe destacar, que sem a presença expressiva de Atividades Centrais e Típicas da ZPC, as Atividades Não Centrais não atrairiam, por si só, um contingente significativo de consumidores, principalmente, os que residem em outros bairros.

Entre os 35 estabelecimentos caracterizados como Atividades Não Centrais destacou-se maior incidência de comércio especializado em servir bebidas em geral, que funcionam nos três períodos do dia e estão distribuídos pelas quatro zonas do subcentro. Destacou-se, também, a presença de salões de cabeleireiro especializados em cortes masculinos, femininos e unissex, sendo que estes também prestam serviços de barbearia e manicure.

Em relação ao comércio e serviços de consumo frequente e pouco frequente, caracterizados na categoria de Atividades Centrais, foram encontrados 70 estabelecimentos, sendo eles: restaurantes, farmácias, pizzarias, lojas de roupas, supermercados, loja de móveis, estúdio fotográfico, clínicas, escritórios e consultórios.

Dentre as atividades mencionadas acima, as que mais se destacaram foram lojas de roupas, calçados e acessórios (masculinos, femininos e infantis), e comércio de alimentos, sendo eles, supermercados, restaurantes e pizzarias.

Estudos Geográficos, Rio Claro, 17(1): 115-140, jan./jun. 2019 (ISSN 1678-698X) http://www.periodicos.rc.biblioteca.unesp.br/index.php/estgeo 
Destacamos, também, na categoria Atividades Centrais, os serviços de profissionais liberais, onde encontramos: clínica de estética, clínica veterinária, escritórios de contabilidade e consultório odontológico. A presença destes serviços confirma o terceiro critério, referente à presença de serviços de profissionais liberais.

Em relação ao quarto critério, relacionado à existência de serviços financeiros, sendo estes, também caracterizados como Atividades Centrais, observamos que o local carece desses serviços, pois, não existem redes bancárias, agências de financiamento, correios e lotéricas instaladas nas ruas Fernando Ferrari e Filomeno João Pires.

No entanto, foram encontrados dois serviços financeiros que acreditamos que vale a pena reforçar: na Rua Fernando Ferrari, no trecho que localiza-se na no final da Vila Industrial, há um local que oferece serviço de pagamento de boletos, faturas e contas de água, energia e telefonia. Há também, anexo ao Supermercado Abevê, um caixa eletrônico 24 horas com serviços dos principais bancos nacionais, localizado no Bairro Jardim São Cristóvão, no final da Rua Fernando Ferrari. Oferece serviços de consulta de saldos e extratos, empréstimos, transferências, saques e pagamentos/agendamentos de convênios e títulos.

Destacamos que esses dois serviços financeiros são um ponto forte para o papel de centralidade intraurbana desempenhado pelo subcentro, pois, de maneira geral, em outros bairros além do centro principal de Dourados, tais serviços não se fazem presente. Sendo assim, atraem parcela significativa dos moradores locais, e, até certo ponto, moradores de outras localidades, pois, para muitos é o local mais próximo para buscarem tais serviços.

Tratando-se do comércio e serviços de consumo frequente e pouco frequente, caracterizados como Atividades Típicos da Zona Periférica Central (ZPC) foram encontrados: conveniências, lojas de assistência técnica, oficinas de motos, distribuidoras de água e gás de cozinha, lojas de tinta e materiais para construção, distribuidora de embalagens, estúdios de tatuagens, oficina de carros, distribuidora de sementes, bicicletarias, metalúrgica, borracharias, casa agropecuária, tapeçaria, lava jatos, loja de sistemas de segurança, tornearia, lojas de som automotivo, marcenarias, loja de alinhamento e balanceamento de veículos, loja de materiais elétricos, loja de refrigeração, loja de brinquedos, distribuidora de catálogos e agencia de turismo, entre outros.

Estes estabelecimentos desenvolvem atividades que necessitam de uma área física maior, neste sentido, normalmente são encontradas fora do centro principal, pois, conforme destacou Corrêa, (2005) a saturação de atividade terciárias no centro principal e a falta de local para o desenvolvimento e expansão de algumas especialidades comerciais faz com que alguns tipos de comércio e serviços se instalem em áreas dispersas do centro principal.

Assim, primeiramente, estes estabelecimentos eram encontrados no centro principal, depois, segundo Horwood e Boyle (1959), passaram a se direcionar para a denominada Zona Periférica Central. No entanto, com o aumento do processo de descentralização, passaram a se localizar, também, nos subcentros.

Foram encontrados na área de pesquisa, 40 estabelecimentos caracterizados como Atividades Típicas da Zona Periférica Central (ZPC). Entre eles, os que mais se destacaram foram às lojas de conveniências. Essas lojas possuem como característica, atrair consumidores locais e de outros bairros. Estes estabelecimentos, também, prestam serviços de entrega, facilitando o atendimento

Estudos Geográficos, Rio Claro, 17(1): 115-140, jan./jun. 2019 (ISSN 1678-698X) http://www.periodicos.rc.biblioteca.unesp.br/index.php/estgeo 
aos consumidores de áreas mais distantes. Isto faz com que se amplie seu raio de influência em relação ao mercado consumidor.

Outros estabelecimentos que se destacaram foram às oficinas e lojas de peças e acessórios para veículos. Foram encontradas oficinas de motos distribuídas por todas as zonas do subcentro. Estão presentes, também, em menor proporção, oficinas de carros, bicicletarias, lojas de reparos (borracharias) e lojas de acessórios automotivos (instalação e manutenção de som).

Outro elemento importante para reforçar a importância dos subcentros é a instalação de comércio pertencente à rede de filiais, que trouxemos aqui como quinto critério.

Segundo Souza (2009, p. 138) "a presença desses estabelecimentos nos subcentros evidencia sua relevância perante o espaço urbano, mostrando que esta área tem um fluxo comercial importante". O referido autor completa dizendo que a centralidade intraurbana desempenhada pelo subcentro "torna interessante à instalação de filiais de lojas já estabelecidas em outros locais da cidade, principalmente, no centro principal".

Os estabelecimentos que possuem filial no Subcentro das ruas Fernando Ferrari e Filomeno João Pires vão desde lojas de assistência técnica e roupas até redes de farmácias e supermercados, como é o caso das redes Max Popular e ABEVÊ.

Vale destacar que o grupo ABEVÊ é uma das maiores redes de supermercado do Mato Grosso do Sul e escolhe estrategicamente os locais mais atrativos para instalar suas filiais, sendo normalmente áreas que já exerçam certa centralidade. Segundo Calixto e Bernardelli (2016, p. 90):

Atualmente, a rede tem lojas distribuídas em cidades como, Dourados, Caarapó, Maracaju, Três Lagoas, Rio Brilhante e Itaporã. Com exceção de Maracaju, onde há duas lojas ABEVÊ, outros municípios do sul do estado possuem somente uma unidade, como no caso de Caarapó, Rio Brilhante e Itaporã, enquanto Dourados, além de sediar a central de compras, possui nove lojas

Neste sentido, o subcentro das ruas Fernando Ferrari e Filomeno João Pires foi uma das áreas eleitas para que esse grupo estabelecesse uma filial de suas lojas. Esse fator reforça o papel de centralidade intraurbana desempenhado pelo subcentro. $\mathrm{Na}$ tabela 04 pode ser observado às lojas que instalaram suas filias na área pesquisada.

Estudos Geográficos, Rio Claro, 17(1): 115-140, jan./jun. $2019 \quad$ (ISSN 1678-698X) http://www.periodicos.rc.biblioteca.unesp.br/index.php/estgeo 
Tabela 04 - Dourados - MS (2018): Estabelecimentos comerciais com filial nas ruas Fernando Ferrari e Filomeno João pires

\begin{tabular}{|c|c|c|}
\hline ESTABELECIMENTO & RAMO DE ATUAÇÃO & $\begin{array}{c}\text { OUTROS BAIRROS/CIDADES } \\
\text { COM FILIAIS }\end{array}$ \\
\hline Stoky Fashion & Comércio de Vestuário & Centro \\
\hline $\begin{array}{l}\text { Conveniência e } \\
\text { Tabacaria Arcanju's }\end{array}$ & Lojas de Conveniência & Jardim Universitário \\
\hline Moto Mania & Oficina de Motos & Vila Industrial \\
\hline Viela Street Wear & Comércio de Vestuário & Centro \\
\hline Qualifarma & Farmácia & Centro \\
\hline $\begin{array}{l}\text { Farmácia Max } \\
\text { Popular }\end{array}$ & Farmácia & Centro \\
\hline Eletrônica Confiança & Assistência Técnica & Centro \\
\hline Supermercado Abevê & Secos e Molhados & $\begin{array}{c}2 \text { Centro, } 2 \text { Jardim Água Boa, } \\
\text { Jardim Paulista, Jardim Canaã, } \\
\text { Jardim Florida, Jardim Clímax / } \\
\text { Caarapó, Maracaju, Três Lagoas, } \\
\text { Rio Brilhante e Itaporã }\end{array}$ \\
\hline Abevê Fácil & Secos e Molhados & $\begin{array}{c}\text { Jardim Água Boa, Centro, Vila } \\
\text { Erondina, Jardim Guanabara e } \\
\text { Jardim Universitário. }\end{array}$ \\
\hline $\begin{array}{l}\text { Despachante } \\
\text { Josefath }\end{array}$ & $\begin{array}{l}\text { Legalização de } \\
\text { Documentos de } \\
\text { Trânsito }\end{array}$ & Centro \\
\hline KZ Store & Comércio de Vestuário & Jardim Ouro Verde \\
\hline Chipa's De Casa & $\begin{array}{l}\text { Comércio de } \\
\text { Alimentos }\end{array}$ & $\begin{array}{l}\text { Jardim Florida, Jardim Água Boa, } \\
\text { Centro }\end{array}$ \\
\hline
\end{tabular}

Fonte: SHIWA, Renato Massao, 2018.

O sexto critério é a presença de serviço cultural e recreativo. Neste fator, o subcentro possui um local denominado de Praça da Juventude, localizado nos limites da Zona 5. Esta Praça, oferece para os moradores locais e de outros bairros atividades como, cursos, palestras, teatro, dança, música, entre outras atividades. $\mathrm{O}$ local possui ainda, uma quadra esportiva, uma pista de skate, um parquinho, uma biblioteca e uma sala de cinema, que também são utilizados pela comunidade. 


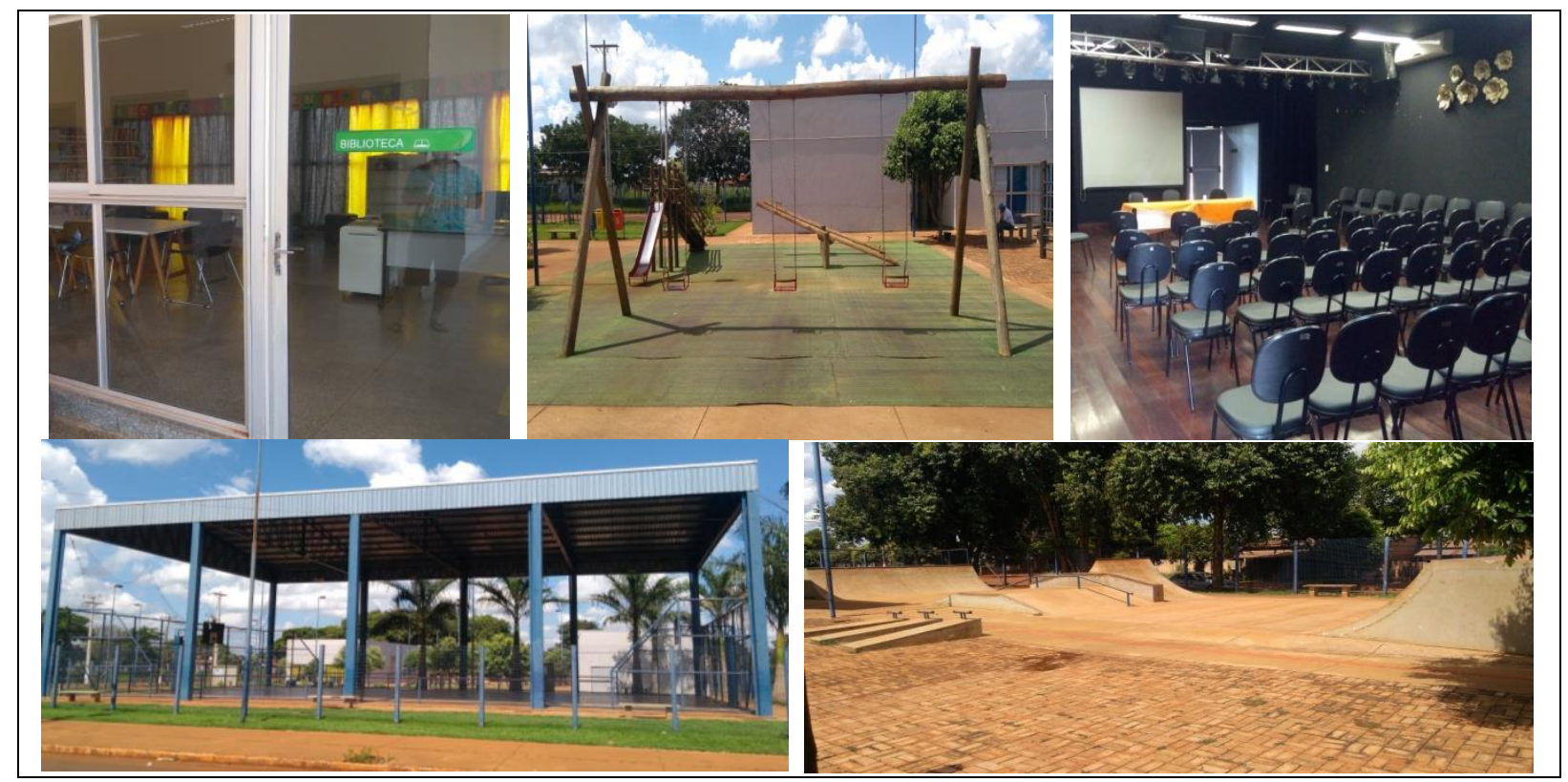

Figura 08 - Dourados - MS (2018): Atividade cultural e recreativa no subcentro das ruas Fernando Ferrari e Filomeno João Pires.

Fonte: SHIWA, Renato Massao, 2018.

O sétimo critério está relacionado aos serviços de transporte coletivo, pois, conforme destacou Duarte (1974) "sendo a área bem servida de meios de transporte e possuindo facilidade de acesso, garante para si importante área de mercado".

Nesse sentido, na referida área, passa o transporte público coletivo que faz a ligação dos bairros Parque das Nações I, Vila Industrial, Jardim São Cristóvão e Jardim João Paulo II com outros bairros da cidade, incluindo o centro principal. $\mathrm{Na}$ área de pesquisa, foram encontrados quatro pontos de ônibus distribuídos ao longo da extensão das ruas, sendo um em cada bairro por onde elas cruzam.

Estudos Geográficos, Rio Claro, 17(1): 115-140, jan./jun. $2019 \quad$ (ISSN 1678-698X) http://www.periodicos.rc.biblioteca.unesp.br/index.php/estgeo 

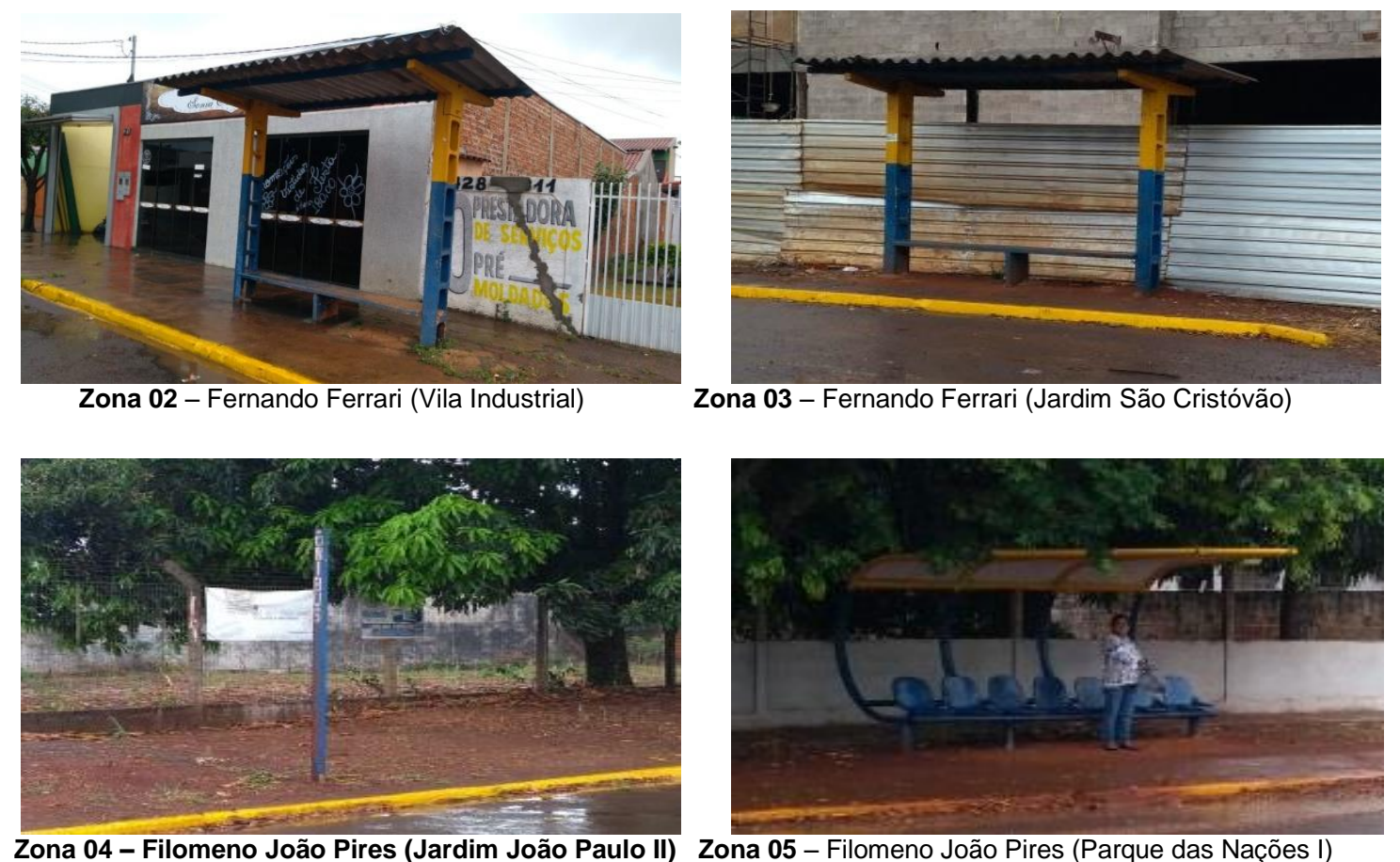

Zona 04 - Filomeno João Pires (Jardim João Paulo II) Zona 05 - Filomeno João Pires (Parque das Nações I)

Figura 09 - Dourados-MS (2018): Pontos de ônibus por onde passa o transporte público no subcentro das ruas Fernando Ferrari e Filomeno João Pires.

Fonte: SHIWA, Renato Massao, 2018.

Em relação aos horários que os ônibus circulam por essas ruas, constatouse que, há alguns anos, a linha passava de hora em hora. Assim sendo, os ônibus eram lotados. Isso gerou alguns acidentes na época e reclamação em função da velocidade acima do permitido e das freadas bruscas. Então, a prefeitura entrou com uma liminar solicitando da empresa de transporte alterações na linha, para que se aumentasse o número de horários (PREFEITURA MUNICIPAL DE DOURADOS, 2017).

Atualmente, os ônibus passam em horários que variam entre 15 minutos e 1 hora, facilitando o acesso das pessoas à área de comércio e serviços. No entanto, ainda existem problemas na linha que faz ligação desses bairros com outras partes da cidade. Entre estes problemas destacam-se: atraso dos ônibus, lotação de passageiros, falta de uma linha de acesso rápido ao centro principal e preço da passagem considerado alto por alguns moradores.

Após submetermos os sete critérios propostos como metodologia de análise, observamos que todos eles estão presentes na área de estudo. No entanto, destacamos que diferentemente do que ocorre nos subcentros das metrópoles, no subcentro analisado em Dourados-MS, esses critérios ainda estão se estruturando. Esse fator aponta uma especificidade das cidades médias, onde a descentralização das atividades terciárias que constituem novas expressões de centralidade intraurbana ainda estão em processo de consolidação.

Estudos Geográficos, Rio Claro, 17(1): 115-140, jan./jun. $2019 \quad$ (ISSN 1678-698X) http://www.periodicos.rc.biblioteca.unesp.br/index.php/estgeo 


\section{CONSIDERAÇÕES FINAIS}

Neste artigo, consideramos as transformações decorrentes do processo de descentralização e que constitui novas expressões de centralidade intraurbana, buscando comprovar a hipótese da pesquisa de que há nas ruas Fernando Ferrari e Filomeno João Pires a formação de um subcentro. Para isso, utilizamos sete critérios embasados na bibliografia sobre o tema.

Em relação ao primeiro critério - predominância de comércio e serviços no uso do solo da área delimitada - observamos que há na área de pesquisa a predominância de uso do solo destinado às atividades terciárias, sendo $51 \%$ de comércio e serviços e $45 \%$ de uso residencial. Esses dados apontam que no subcentro analisado, o número de residências ainda é considerável, o que indica que a descentralização das atividades comerciais e de serviço ainda encontra-se em processo de consolidação. No entanto, a presença de terrenos não edificados e de salões que encontram-se em construção ou para alugar indicam para a possiblidade de aumento das atividades de comércio e serviços e, por consequência, o reforço do papel de subcentro.

A partir do segundo critério - maior concentração de Atividades Centrais e Típicas da Zona Periférica Central (ZPC) em relação às Atividades Não Centrais constatou-se $75,9 \%$ de atividades classificadas nas categorias de Atividades Centrais e Típicas da Zona Periférica Central (ZPC), reforçando a existência de um subcentro por serem atividades de uso frequente e pouco frequente que atraem consumidores de outras localidades. Apesar disso, observou-se que no caso de Dourados, no subcentro das ruas Fernando Ferrari e Filomeno João Pires existem alguns estabelecimentos classificados como Atividades Não Centrais, que também atendem consumidores de outras localidades. Assim, as Atividades Não Centrais formam um conjunto com as demais categorias de atividades. Nesta lógica, consideramos que a centralidade exercida pelo local se constitui pelo conjunto das atividades nele presente.

Sobre o terceiro critério - presença de serviços de profissionais liberais foram observados diversos serviços de profissionais liberais: clínica odontológica, clínica veterinária, Clínica de estética, escritório de advocacia e, predominantemente, escritórios de contabilidade. Durante a pesquisa de campo, observamos que a incidência de contadores ocorre em razão de boa parte de seus clientes possuírem comércios no local, sendo assim, a proximidade com os clientes, segundo esses profissionais, facilita um contato mais pessoal. Além disso, de acordo com os mesmos, instalar seus estabelecimentos em uma área que concentra atividades comerciais pode possibilitar futuros negócios com outros comerciantes.

Quanto ao quarto critério - existência de serviços financeiros - identificamos outra especificidade na área de pesquisa. Nas metrópoles, pelo fato dos subcentros já estarem mais consolidados, contam com serviços financeiros como, bancos, lotéricas, correios e financiadoras. No caso de Dourados, essas atividades ainda concentram-se no centro principal. No entanto, destacamos a importância de duas atividades encontradas no subcentro das ruas Fernando Ferrari e Filomeno João Pires que buscam suprir parte das necessidades dos consumidores, sendo elas, uma farmácia e o Supermercado ABEVÊ, que por meio de convênios realizam algumas atividades como depósitos, saques, transferências, pagamento de contas e boletos.

Estudos Geográficos, Rio Claro, 17(1): 115-140, jan./jun. $2019 \quad$ (ISSN 1678-698X) http://www.periodicos.rc.biblioteca.unesp.br/index.php/estgeo 
O quinto critério - instalação de comércio pertencente à rede de filiais - é outro elemento que destacamos. No caso do subcentro pesquisado, foram encontradas filiais de: lojas de vestuário, conveniência, oficina de motos, farmácia, assistência técnica, despachante e comércio de alimentos. Este fator mostra que a área tem atraído estabelecimentos de diversos ramos de atuação, levando-se em conta a realidade das cidades médias. Entre as filiais que se instalaram no local, encontra-se desde estabelecimentos de pequenos e médios empreendedores, que ampliaram seus negócios para esta área, quanto de maiores grupos como 0 Supermercado ABEVÉ e a rede de farmácias "Max Popular" que costumam procurar locais estratégicos para instalar suas filiais.

No sexto critério - serviço Cultural e recreativo - identificamos que na área de pesquisa, os serviços de cultura e lazer tais como: biblioteca, sala de informática, sala de cinema, pista de skate, parque, quadra esportiva, entre outros, podem ser encontrados em um só lugar - a Praça da Juventude, que possui importância para o local e atrai pessoas, inclusive, de outras áreas da cidade.

Já o sétimo critério - serviços de meios de transporte coletivo - segundo (Duarte, 1974) é fundamental para assegurar ao subcentro uma área de mercado, pois, se o local possuir uma boa rede de transporte e comunicação, polarizará maior número de consumidores. Neste sentido, observamos que apesar dos problemas apresentados pelo transporte público que realiza o trajeto (atraso dos ônibus, lotação e preço da passagem considerado alto por alguns moradores), o acesso ao local tem melhorado por meio do aumento do número de linhas. Atualmente, os ônibus passam em horários que variam entre 15 minutos e 1 hora, sendo que antes só passavam a cada 1 hora. Isto mostra que a circulação de pessoas por essas ruas têm aumentado, exigindo novos horários. Além disso, os pontos de ônibus encontram-se distribuídos por toda a extensão das ruas Fernando Ferrari e Filomeno João Pires, o que facilita e otimiza a locomoção dos consumidores.

No que se refere à comunicação, destacamos a importância que as redes sociais têm apresentado para a divulgação do comércio e serviços do local e, consequentemente, a atração de consumidores para essa área. Esse fator, nos tempos atuais, é uma importante ferramenta que impulsiona os negócios e as atividades comerciais.

Dessa forma, por meio do que foi constatado na área de pesquisa, consideramos a formação de um subcentro marcado pela presença de atividades de comércio e serviços, que tem poder de atração de consumidores de outras localidades da cidade, potencializando os fluxos e constituindo e reforçando um papel de centralidade intraurbana.

Ainda que essa nova expressão de centralidade tenha tido força a partir do processo de descentralização pelo qual passaram/passam as cidades médias, fazendo com que surgissem novas áreas centrais intraurbanas, vale ressaltar esse não é um processo pronto e acabado, mas que se encontra em constante redefinição.

Este trabalho procurou considerar de que forma o papel regional que Dourados passou a desencadear, sobretudo, a partir da década de 1970, um processo de expansão da malha urbana, decorrente da atividade loteadora.

Dentre os loteamentos lançados nesse contexto, estão a Vila Industrial, o Jardim São Cristóvão, o Jardim João Paulo II e o Parque das Nações I, onde se localiza o subcentro das ruas Fernando Ferrari e Filomeno João Pires. No entanto, a descentralização das atividades terciárias para estas ruas só passa a ocorrer a partir

Estudos Geográficos, Rio Claro, 17(1): 115-140, jan./jun. 2019 (ISSN 1678-698X) http://www.periodicos.rc.biblioteca.unesp.br/index.php/estgeo 
da década de 1990. Primeiramente, pelo distanciamento desses loteamentos em relação ao centro principal, implicando em dificuldade de acesso dos moradores à área da cidade onde encontrava-se a maior oferta de comércio e serviços. Posteriormente, quando ocorre o processo de ocupação mais efetiva dos loteamentos e melhoria na infraestrutura, equipamentos e serviços, tais como, asfalto, iluminação pública e rede de transporte.

No caso do subcentro das ruas Fernando Ferrari e Filomeno João Pires, a concentração de comércio e serviços deu-se a partir de pequenos empreendedores que ao longo dos anos, foram implantando seus estabelecimentos, fazendo com que o local fosse assumindo centralidade. No entanto, conforme observado na pesquisa, sobretudo, a partir de 2010, o local passa a atrair, também, grupos ligados a rede como, Supermercado ABEVÊ e Farmácia Max Popular.

Por último, vale destacar que consideramos que as questões/discussões apresentadas nesta pesquisa poderão contribuir com futuros estudos acerca do papel de subcentros em cidades médias, principalmente, em razão de maior parte dos estudos ainda serem voltados à realidade das áreas metropolitanas.

\section{REFERÊNCIAS}

BURGESS, E. El crescimento de la ciudad: introducción a un proyecto de investigación. In: Estudios de ecologia humana. G. A. Theodorsom. Coord. Barcelona, Labor. 1974, p. $69-81$.

CALIXTO, Maria J. M. S. O processo de consolidação da centralidade de Dourados - MS na rede urbana: uma contribuição para a análise de uma cidade média. 2011, 117f. Relatório (Pós-doutorado em Geografia) - Centro de Ciências Matemáticas e da Natureza, Universidade Federal do Rio de Janeiro. Rio de Janeiro, 2011.

O papel exercido pelo poder público local na (re)definição do processo de produção, apropriação e consumo do espaço urbano em Dourados-MS. 2000. 295f. Tese (Doutorado em Geografia) - Faculdade de Ciências e Tecnologia, Universidade Estadual Paulista, Presidente Prudente, 2000.

CALIXTO, Maria J. M. S; BERNARDELLI, Mara L. F. da H. Dourados-MS: uma cidade média entre papéis regionais e a dinâmica globalizada. In. SPOSITO, Maria Encarnação B; MAIA, Doralice Sátyro. (org.) Agentes econômicos e reestruturação urbana e regional: Dourados e Chapecó. São Paulo: Cultura Acadêmica. 2016. p. 29 a 165.

CASTELLO BRANCO, Maria L.G. Algumas considerações sobre a identificação sobre as cidades médias. In. SPOSITO, Maria E. B. (org.) Cidades médias: espaços em transição. São Paulo: Expressão Popular. 2007, p. 89 a 112.

DOURADOS (Município). SEPLAN, Secretaria Municipal de Planejamento. Malha Municipal Digital. IBGE, 2005.

SEPLAN, Secretaria Municipal de Planejamento. Planta Urbana: banco de dados 2017. Dourados, 2017.

Estudos Geográficos, Rio Claro, 17(1): 115-140, jan./jun. 2019 (ISSN 1678-698X) http://www.periodicos.rc.biblioteca.unesp.br/index.php/estgeo 
DUARTE, Haidine da Silva Barros. A cidade do Rio de Janeiro: descentralização das atividades terciárias. Os centros funcionais. In: Revista Brasileira de Geografia, Rio de Janeiro, 36 (1), p. 53 - 98, jan./mar., 1974.

GOOGLE MAPS. Mapa de Dourados. Disponível em: <http://mapas.google.com.> Acesso em: 20 mar. 2017.

INSTITUTO BRASILEIRO DE GEOGRAFIA E ESTATÍSTICA (IBGE). Contagem da população: Banco de dados 2010. Disponível em: <https://cidades.ibge.gov.br>. Acesso em: 15 mar. 2017.

REGIÕES DE INFLUÊNCIA DAS CIDADES (REGIC). Relatório, Rio de Janeiro, 2008.

SOUZA, Marcus V. M. de. Cidades médias e novas centralidades: análise dos subcentros e eixos comerciais em Uberlândia (MG). 2009. 236f. Dissertação (Mestrado em Geografia) - Universidade Federal de Uberlândia, Uberlândia, 2009.

SPOSITO, Maria Encarnação B. A gestão do território e as diferentes escalas da centralidade urbana. Território, Rio de Janeiro, LAGET/UFRJ, n.4, jan./ jun., 1998, p. 27-37.

Novas formas comerciais e redefinição da centralidade intraurbana. In: Textos e contextos para a leitura geográfica de uma cidade média, Presidente Prudente, 2001, p. $235-255$.

STROHAECKER, Tânia Marques. A zona periférica ao centro: uma revisão bibliográfica. In: Revista brasileira de Geografia, Rio de Janeiro, 50 (4), 171 - 183, out./dez. 1988.

VILLAÇA, Flavio. Espaço intraurbano no Brasil. São Paulo: Studio Nobel: FAPESP: Lincoln Institute, 2001. 